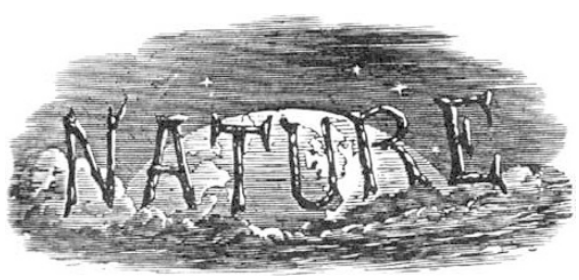

SATURDAY, MARCH 3, I923.
PAGE

Sequence in School Geometry

The Development of the Quantum Theory. By Prof. H. S. Allen .

History of Medicine

Frontier Tribes of Assam. (Ilinstrated.) .

Our Bookshelf

Letters to the Editor :-

The Function of Mendelian Genes.-Julian S.

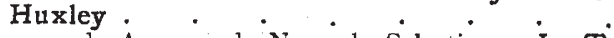
Age and Area and Natural Selection.-j. $\quad \dot{T}$. Cunningham .

The Value of $e / m$.-Raymond T. Birge :

Sir Christopher Wren's Science Museum. (Illustrated.) - R. T. Gunther .
esla Spectra of Complex Compounds.-Prof. Victor

Tesla Spectra of Complex Compounds.-Prof. Victor

Henri; J. K. Marsh, and Prof. A. W. Stewart

Calendar Reform.-L. C. W. Bonacina

Time Relations in a Iream.-H. F. Biggs

The Ascent of Elvers in Egyptian Waters - $\dot{G}$. W. Pranscription of Russian Proper Names. - Prof. Bohuslav Brauner
erapath's Artificial Tourmalines. - Dr. M. Nierenstein . .

The Mechanism of Audition. - Frederick W. Kranz

Spiranthes autumnalis. -E. Philip Smith; John B.

The Drayson Paradox.-A. H. Barley; The Writer The Naming of Elements. - $\dot{\mathrm{D} r}$ Norman $R$. Campbell

Sarsen Stones $-\dot{\mathbf{C}}$. Carus- $\dot{W}$ ilson

Poisoning by Illuminating Gas

Imperial College of Science and Technology. OPEN-

ing of THE NeW Botany BuIlding (Plant TeChNOI.OGY). (lllustrated.).

Obituary :-

Dr. C. P. Goerz. By J. W. F.

The Hon. R. C. Parsons .

Mr. W. M. Hutchings

Current Topics and Events

Our Astronomical Column

Research Items

The Unit Activity of Animal Organs

Climates of the Past. By G. A. J. C.

Studies on Phytophthoras

Aeronautical Research Committee.

The Hydrautomat

University and Educational Intelligence.

Societies and Academies .

Official Publications Received :

Diary of Societies .

Editorial and Publishing Offices.

MACMILLAN \& CO., LTD..

ST. MARTIN'S STREET, LONDON, W.C.2.

Advertisements and business letters should be addressed to the Publishers.

Editorial communications to the Editor.

\section{Sequence in School Geometry.}

THERE is discontent as to the condition of geometry teaching in schools, and in the search for remedies the question has been reopened whether there should be an " agreed" sequence. It appears from the report summarised in NATURE of February 24, p. $27 \mathrm{I}$, that 90 per cent. of those members of the Assistant Masters' Association who replied to a questionnaire voted for such a sequence, but there is the significant note, "The figures cannot be more than approximately correct, as some of the replies were difficult to interpret." It may be worth while to consider the question itself: what is meant by a "sequence" ; for, unless we are clear about this, the question is ambiguous, and discussion, to say nothing about voting, may be wide of the mark.

Fifty, forty, even thirty years ago the pathway through school (and even college) mathematics was beset with the notice "Verboten." A boy might not use algebra in doing arithmetic; analysis was forbidden in geometry papers ; calculus in doing analytical geometry or mechanics; while to mention a sine or cosine in the natural philosophy paper of a certain examining body would have been to pull the very whiskers of death.

Such, at least, were the facts as understood by those still in statu pupillari and as impressed upon them by their immediate teachers, whatever liberty the higher powers - the examiners-may have exercised in practice. But, above all, there must be no departure from the order of Euclid, and to use a later proposition in the proof of an earlier was mortal sin.

Now, here a distinction should be made : in part Euclid's order is essential to his general argument; but in part it is not and is merely matter of chance or convenience. For example, I. I6 (that the exterior angle of a triangle is greater than either of the interior opposite angles) of necessity comes before I. 32 (that the exterior angle is equal to the two together); and to use the latter to prove the former is a real error, betraying want of grasp of Euclid's argument.

On the other hand, his Sixth Book (on proportion and similar figures) does not depend on any proposition subsequent to I. $3^{6}$ and I. $3^{8}$ (that parallelograms and triangles on equal bases and between the same parallels are equal). Consequently, to use VI. 8 to prove I. 47 would not have been false logic, or an essential departure from his system, but merely a variation from the particular method he chose to adopt.

By sequence, then, we may mean either essential sequence, departure from which destroys the validity of the argument, or merely the arrangement of the subject-matter in an order dictated by convenience 
or taste, not by logic. Now, what is in the mind of those who desire a uniform sequence, whether agreed or imposed? We do not know ; but it may be useful to consider the case for both kinds of sequence-that of logic and that of convenience. We will take the latter first.

It would, no doubt, be convenient, as boys frequently move from school to school, if all followed the same general order-taking, for example, the circle before similarity or vice versa. But agreement on an open question like this is unlikely, for each of the equally admissible orders would find strong advocates, and teachers keenly interested in their work would not willingly surrender their liberty.

The graver question, of course, is as to the logical sequence. But in fact, the current practice of schools has eliminated the question in this form; for the practice is now widespread (and the Assistant Masters' Association's Report will give it further currency) of beginning the formal study of geometry at a point where a sufficiently broad quasi-axiomatic basis has been established, namely, the conditions of congruency of triangles and the angle properties of parallel lines.

This means in effect the abandonment, or at least the postponement, of most of Euclid's propositions up to I. 32. Experience has shown that many of these individual propositions are not really grasped by the ordinary boy, and if these are omitted others become unnecessary, as they are mere links. between the others. The advantage of the omission is that a boy can begin where the work is easy instead of where it is most difficult.

Two questions of great importance emerge, however, and it is probably to these that those who are, quite justly, dissatisfied with the present state of things should address themselves. First, how can we recover anything that we have lost by departure from the strict traditional system ; and second, when, if at all, should boys be introduced to the initial difficulties which have been evaded?

As to the former, it is suggested that the proper guiding word is not "sequence," but " interconnexion" - that the idea required is not so much that of a single thread, as of a network of argument. It is an excellent practice to take a known proposition and trace its connexions backward. Thus the property of a cyclic quadrilateral depends on the relation between the angle at the centre and that at the circumference ; this, again, depends on two early propositions, namely, the exterior angle of a triangle is equal to the two interior angles, and the angles at the base of an isosceles triangle are equal ; the former depends on the angle properties of parallels, the latter on congruence. Following this process, wherever we begin, we always get back to one or both of these fundamental principles.

This illustration shows how grasp of sequence can be strengthened; as illustration of interconnexion take Pythagoras's proposition. It may be proved, as in Euclid, by use of parallelograms and congruent triangles; or by variants, using parallelograms only, which, however, depend on congruent triangles; but again it may be proved by the use of similar triangles (Euclid VI. 8). But similar triangles rest on the angle properties of parallels and on Euclid VI. 2, or the equivalent proposition as to the segments made on transversals by parallels, and this, again, depends on congruence. Similarly, it seems unwise to neglect either of the proofs of Euclid III. 35, 36 (rectangles contained by segments of chords); the proof by similarity is the easier and shows the inwardness of the proposition better; Euclid's proof brings out the important fact that the rectangle is equal to $k^{2}-r^{2}$, the "power of the point." Illustrations might be multiplied; but these will suffice to indicate what is meant, the habit of tracing connexions which gives mastery of the whole, and, it may be added, greatly increased power in what, after all, is the essential thing, the art of doing riders.

The second question does not, perhaps, as yet admit of so definite an answer: when and how far should pupils be asked to face the initial difficultiescongruence, parallelism, and the link propositions (e.g. inequalities) necessary for dealing with them? A partial answer may be given with some confidence : not until they have mastered the rest of the work and have gained power in solving problems. Beyond this it is not safe to dogmatise, but if geometry. is worth studying for its own sake, for its beauty and essential interest, and not merely as an exercise in logic, it is quite possible, and, indeed, for most boys probable, that they will gain more by going onby studying the ordinary developments not contained in Euclid, e.g. coaxal circles, pole and polar, inversion, etc., and geometrical conics, to say nothing of solid geometry - than by going back to examine first principles. Still in sixth form work, possibly in favourable circumstances in a fifth form, time might well be found for this; properly handled it would arouse great interest and would certainly be well within the power of the boys-as it is not within that of a third form. It involves, above all, the parallels axiom and some consideration of the relationship between axioms and definitions; in fact, it is quite as much a philosophic as a mathematical question. Its treatment would be rendered more effective by some knowledge of non-Euclidean geometry on the part of the teacher. 